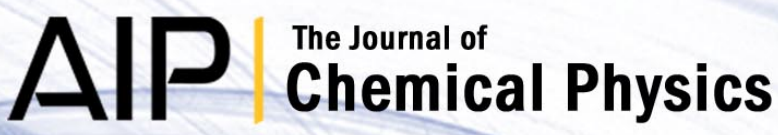

Kinetics of the sulfur oxidation on palladium: A combined in situ x-ray photoelectron spectroscopy and density-functional study

Karin Gotterbarm, Nicola Luckas, Oliver Höfert, Michael P. A. Lorenz, Regine Streber et al.

Citation: J. Chem. Phys. 136, 094702 (2012); doi: 10.1063/1.3687676

View online: http://dx.doi.org/10.1063/1.3687676

View Table of Contents: http://jcp.aip.org/resource/1/JCPSA6/v136/i9

Published by the American Institute of Physics.

Additional information on J. Chem. Phys.

Journal Homepage: http://jcp.aip.org/

Journal Information: http://jcp.aip.org/about/about_the_journal

Top downloads: http://jcp.aip.org/features/most_downloaded

Information for Authors: http://jcp.aip.org/authors

\section{ADVERTISEMENT}

\section{ACCELERATE COMPUTATIONAL CHEMISTRY BY 5X. TRY IT ON A FREE, REMOTELY-HOSTED CLUSTER. \\ NVIDIA.}




\title{
Kinetics of the sulfur oxidation on palladium: A combined in situ x-ray photoelectron spectroscopy and density-functional study
}

\author{
Karin Gotterbarm, ${ }^{1, \text { a) }}$ Nicola Luckas, ${ }^{2, \text { a) }}$ Oliver Höfert, ${ }^{1}$ Michael P. A. Lorenz, ${ }^{1}$ \\ Regine Streber, ${ }^{1}$ Christian Papp, ${ }^{1, b)}$ Francesc Viñes, ${ }^{2, b)}$ Hans-Peter Steinrück, ${ }^{1,3,4}$ \\ and Andreas Görling ${ }^{2,4}$ \\ ${ }^{1}$ Lehrstuhl für Physikalische Chemie II, Universität Erlangen-Nürnberg, Egerlandstr. 3, \\ 91058 Erlangen, Germany \\ ${ }^{2}$ Lehrstuhl für Theoretische Chemie, Universität Erlangen-Nürnberg, Egerlandstr. 3, \\ 91058 Erlangen, Germany \\ ${ }^{3}$ Erlangen Catalysis Resource Center (ECRC), Universität Erlangen-Nürnberg, Egerlandstr. 3, \\ 91058 Erlangen, Germany \\ ${ }^{4}$ Interdisciplinary Center for Interface Controlled Processes, Egerlandstr. 3, 91058 Erlangen, Germany
}

(Received 29 November 2011; accepted 2 February 2012; published online 1 March 2012)

\begin{abstract}
We studied the reaction kinetics of sulfur oxidation on the $\operatorname{Pd}(100)$ surface by in situ high resolution $\mathrm{x}$-ray photoelectron spectroscopy and ab initio density functional calculations. Isothermal oxidation experiments were performed between 400 and $500 \mathrm{~K}$ for small amounts $(\sim 0.02 \mathrm{ML})$ of preadsorbed sulfur, with oxygen in large excess. The main stable reaction intermediate found on the surface is $\mathrm{SO}_{4}$, with $\mathrm{SO}_{2}$ and $\mathrm{SO}_{3}$ being only present in minor amounts. Density-functional calculations depict a reaction energy profile, which explains the sequential formation of $\mathrm{SO}_{2}, \mathrm{SO}_{3}$, and eventually $\mathrm{SO}_{4}$, also highlighting that the in-plane formation of $\mathrm{SO}$ from $\mathrm{S}$ and $\mathrm{O}$ adatoms is the rate limiting step. From the experiments we determined the activation energy of the rate limiting step to be 85 $\pm 6 \mathrm{~kJ} \mathrm{~mol}^{-1}$ by Arrhenius analysis, matching the calculated endothermicity of the SO formation. (C) 2012 American Institute of Physics. [http://dx.doi.org/10.1063/1.3687676]
\end{abstract}

\section{INTRODUCTION}

Palladium is a highly important material in catalysis. It is an essential component of various commercial catalysts, such as the three-way catalyst, ${ }^{1-4}$ nowadays in use for the treatment of exhaust gases in automotives. Palladium is of common use also in the petrochemical industry ${ }^{5}$ and for the large scale production of fine chemicals. ${ }^{6}$ Focusing on the three-way catalyst, sulfur-containing compounds can lead to catalyst poisoning since they are omnipresent in the fuel feedstocks, i.e., crude oil. ${ }^{7}$ Once the fuel is burned, atomic sulfur or $\mathrm{SO}_{\mathrm{x}}$ $(x=1-4)$ are formed and can attach to the catalyst palladium phase, thus leading to the poisoning of the catalyst, reducing its lifetime and effectiveness. ${ }^{8,9}$

Therefore, a major goal in the technical operation of catalysts is to minimize this poisoning. ${ }^{10,11}$ One way to achieve this is by the removal of sulfur in the early processing of the used feedstocks by hydrodesulfurization methods, even though a complete removal is, unfortunately, not possible. ${ }^{12}$ Hence, minor amounts of sulfur are always left in the produced fuels. The adsorption of these sulfur traces on the catalyst surface can lead to a substantial decrease of its reactivity. ${ }^{10,11,13-21}$ First endeavors to understand the effects of sulfur on the electronic structure, the adsorption capacity, and reactivity of palladium have been undertaken, ${ }^{22}$

\footnotetext{
a) K. Gotterbarm and N. Luckas contributed equally to this work.

b) Authors to whom correspondence should be addressed. Electronic addresses: Christian.Papp@chemie.uni-erlangen.de and Francesc.Vines@ chemie.uni-erlangen.de.
}

whereas the regeneration by means of sulfur oxidation has not been addressed so far from a fundamental point of view.

A basic understanding of poisoning on the molecular level can be gained by combining $a b$ initio calculations and in situ experiments on single crystal catalyst surfaces. ${ }^{22-25}$ Low indexed surfaces are shown to be the major interface of metal nanoparticles in heterogeneous catalysts. Such surfaces are thus expected to be a major part of a three way catalyst for exhaust gas cleaning in automobiles. First in situ studies of the interaction of sulfur with one other major constituent of a three way catalyst, platinum, have been published lately allowing now for a wider view of the possible reactions and reaction kinetics on the catalyst for a deeper understanding of the processes involved. Past studies have shown that atomic sulfur adsorbs on four-fold hollow sites of the $\operatorname{Pd}(100)$ surface. $^{23,24}$ These sulfur atoms lower the surface activity by blocking the available adsorption/reaction sites on the surface due to sterical hindrance. ${ }^{19,26,27}$ Such blocking has been found to affect both hydrogen and oxygen adatoms ${ }^{27}$ which are used to regenerate the catalyst through either a reductive mechanism (formation and desorption of $\mathrm{H}_{2} \mathrm{~S}$ ) ${ }^{12}$ or an oxidative mechanism (formation and desorption of $\mathrm{SO}_{2}$ or $\mathrm{SO}_{3}$ ). ${ }^{28}$ The only study on a thermal oxidation reaction is an early temperature programmed desorption study, ${ }^{29}$ which included isothermal experiments. However, no experiments concerning the reaction mechanism, the surface species formed during the process, and the reaction barriers were presented. This lack of experimental data and insight is due to the fact that the necessary in situ techniques were developed only lately. 
In this work, we provide a detailed description of the oxidation of sulfur atoms adsorbed on a $\mathrm{Pd}(100)$ surface through a combination of in situ X-ray photoelectron spectroscopy (XPS) and $a b$ initio density-functional (DF) calculations. The results allow to clearly identify all reaction intermediates, such as $\mathrm{SO}_{2}, \mathrm{SO}_{3}$, and $\mathrm{SO}_{4}$, and to determine the relevant activation energies of the reaction pathway.

\section{EXPERIMENTAL}

The XPS measurements were performed at the synchrotron facility BESSY II in Berlin at beamline U49/2 PGM1 with a transportable setup ${ }^{30}$ equipped with an electron energy analyzer (Omicron EA 125 U7 HR), a low energy electron diffraction optics, a capillary array doser system, a quadrupole mass spectrometer for residual gas analysis, and a three-stage supersonic molecular beam.

The sample was cleaned from sulfur and other contaminations (e.g., carbon) by exposure to $\mathrm{O}_{2}$ at $300 \mathrm{~K}$, followed by heating to $970 \mathrm{~K}$ to desorb excess oxygen. Final cleanliness was checked by XPS. S $2 p$ spectra were collected with a total resolution of $110 \mathrm{meV}$ at a photon energy of $260 \mathrm{eV}$. The acquisition time was $9 \mathrm{~s}$ per spectrum. All XP spectra were recorded at normal emission. Small coverages of atomic sulfur ranging from 0.01 to $0.03 \mathrm{ML}$ were prepared by dosing $\mathrm{H}_{2} \mathrm{~S}$ with background pressures ranging from 1 to $3 \times 10^{-9}$ mbar and at temperatures below $200 \mathrm{~K}$. Subsequently the sample was flashed to $700 \mathrm{~K}$ to desorb hydrogen. Oxygen was dosed directly onto the sample by the supersonic molecular beam at the denoted temperatures. The thermal evolution of atomic sulfur coadsorbed with oxygen was followed by temperature programmed XPS (TPXPS) ${ }^{31}$ with a linear heating rate of $0.5 \mathrm{~K} \mathrm{~s}^{-1}$.

The sulfur coverages were calibrated using a $c(2 \times 2)$ overlayer of $S$ with a coverage $\left(\Theta_{S}\right)$ of $0.5 \mathrm{ML},{ }^{23,24}$ which was prepared by dosing $\mathrm{H}_{2} \mathrm{~S}$ onto the $\mathrm{Pd}(100)$ surface at $300 \mathrm{~K}$, followed by heating to $550 \mathrm{~K}$ in order to desorb $\mathrm{H}_{2}$, and subsequently cooling down to $300 \mathrm{~K}$; this procedure was repeated until saturation was reached. All S $2 p$ spectra used for the calibration were collected with a photon energy of $380 \mathrm{eV}$ in order to minimize photoelectron diffraction effects. The $\mathrm{O} 1 \mathrm{~s}$ spectra were recorded at a photon energy of $650 \mathrm{eV}$ before and after each experiment. Unfortunately, the Pd $3 p_{3 / 2}$ peak appears at similar binding energies, thus complicating the evaluation of the $\mathrm{O} 1 \mathrm{~s}$ data. For calibration of the spectra, $\mathrm{O}_{2}$ was dosed by the molecular beam at $300 \mathrm{~K}$, leading to a $p(2 \times 2)$ overlayer of atomic oxygen with a coverage of $0.25 \mathrm{ML} .{ }^{24}$ All spectra are referenced to the Fermi level. Before fitting the XPS data a straight line and additionally a Shirley background ${ }^{32}$ was subtracted from the raw data. The S $2 p$ spectra were fitted with doublets of asymmetric Doniach-Sunjic ${ }^{33}$ functions that are each convoluted with a Gaussian function. The area ratio of 2:1 and the splitting of $1.20 \mathrm{eV}$ of the $\mathrm{S} 2 p_{3 / 2}$ and $\mathrm{S} 2 p_{1 / 2}$ peaks are the same for all $\mathrm{SO}_{\mathrm{x}}(\mathrm{x}=1-4)$ species observed.

\section{COMPUTATIONAL METHODS}

The DF calculations were carried out employing Vienna $\mathrm{Ab}$ initio Simulation Package (VASP). ${ }^{34}$ The projector aug- mented wave method has been used to represent the atomic cores. ${ }^{35}$ This approach allows one to obtain converged results with a cutoff kinetic energy of $415 \mathrm{eV}$ for the plane wave basis set. A Monkhorst-Pack grid of $9 \times 9 \times 1$ was used to select the special k-points for numerical integrations in reciprocal space. The oxygen-covered $\operatorname{Pd}(100)$ surface has been modelled by a four-layer slab $c(2 \times 2)$ supercell adding one or two oxygen atoms adsorbed on a hollow $(h)$ site, corresponding to 0.125 and $0.25 \mathrm{ML}$ coverage, as found in the experiments. ${ }^{24}$ More details of the model, the slab representing the surface, as well as of the isolated $\mathrm{SO}_{\mathrm{x}}(\mathrm{x}=1-4)$ species, and the $\mathrm{S}$ and $\mathrm{O}$ atoms can be found elsewhere. 8,36 To allow for a comparison with previous studies ${ }^{8,25,36-39}$ calculations have been carried out using the Perdew-Wang ${ }^{40}$ (PW91) exchange-correlation functional.

Geometry optimizations were performed using a conjugated gradient algorithm and applying a Gaussian smearing of $0.2 \mathrm{eV}$ for the electron occupancy to speed up convergence, although final energy values were corrected to $0 \mathrm{~K}$ (no-smearing). Forces acting on atoms were required to be less than $0.03 \mathrm{~kJ} \mathrm{~mol}^{-1} \mathrm{pm}^{-1}$.

The adsorption energy, $E_{a d s}^{A / B}$, of a given species $A(\mathrm{~S}, \mathrm{O}$, or $\mathrm{SO}_{\mathrm{x}}$ ), on a given substrate $B$ is defined according to the following equation:

$$
E_{a d s}^{A / B}=-E_{A / B}+\left(E_{A}+E_{B}\right),
$$

where $E_{A / B}$ is the energy of the complete system where $A$ is adsorbed on the substrate $B$ and, $E_{A}$ and $E_{B}$ are the energies of the isolated species $A$ and bare substrate $B$, respectively. Note that with this definition the adsorption energy is positive if the adsorbate is bound to the substrate, with larger adsorption energy indicating stronger bonding.

Core level shifts (CLS) of the S $2 p$ levels have been calculated within the final state approximation following a procedure described in the past, ${ }^{25,41-43}$ within the Janak-Slater approach, in which only half an electron is excited from the core level to the valence region and placed in the lowest unoccupied orbital. ${ }^{44}$ For more details of the CLS estimates, we refer to the literature. ${ }^{2,45}$

Finally, the notation of different adsorption sites used throughout the study follows that suggested earlier. ${ }^{8,25,36-39}$ In short, for any given species and adsorption mode, $\eta^{x}$ and $\mu^{y}$ keys denote that $x$ atoms of the molecule $\left(\eta^{x}\right)$ are bound to $y$ surface $\mathrm{Pd}$ atoms $\left(\mu^{y}\right)$.

\section{RESULTS AND DISCUSSION}

In order to obtain an overview of the relevant surface reactions and intermediates, we first investigated the thermal evolution of a coadsorbed sulfur (0.034 ML) and oxygen layer ( $0.23 \mathrm{ML}$ ) by TPXPS; the corresponding S $2 p$ spectra for selected temperatures are depicted in Figure 1(a). For convenience only the $S 2 p_{3 / 2}$ peaks are tagged. To show the temperature-induced changes more clearly a color-coded density plot is presented in Figure 1(b). Finally, the quantitative analysis of the spectra is depicted in Figure 1(c).

The S $2 p$ spectrum prior to oxygen exposure shows a doublet with the $\mathrm{S} 2 p_{3 / 2}$ (S 2p $p_{1 / 2}$ ) peaks located at 161.9 (163.1) eV. After exposure to oxygen, the peaks shift $0.1 \mathrm{eV}$ 


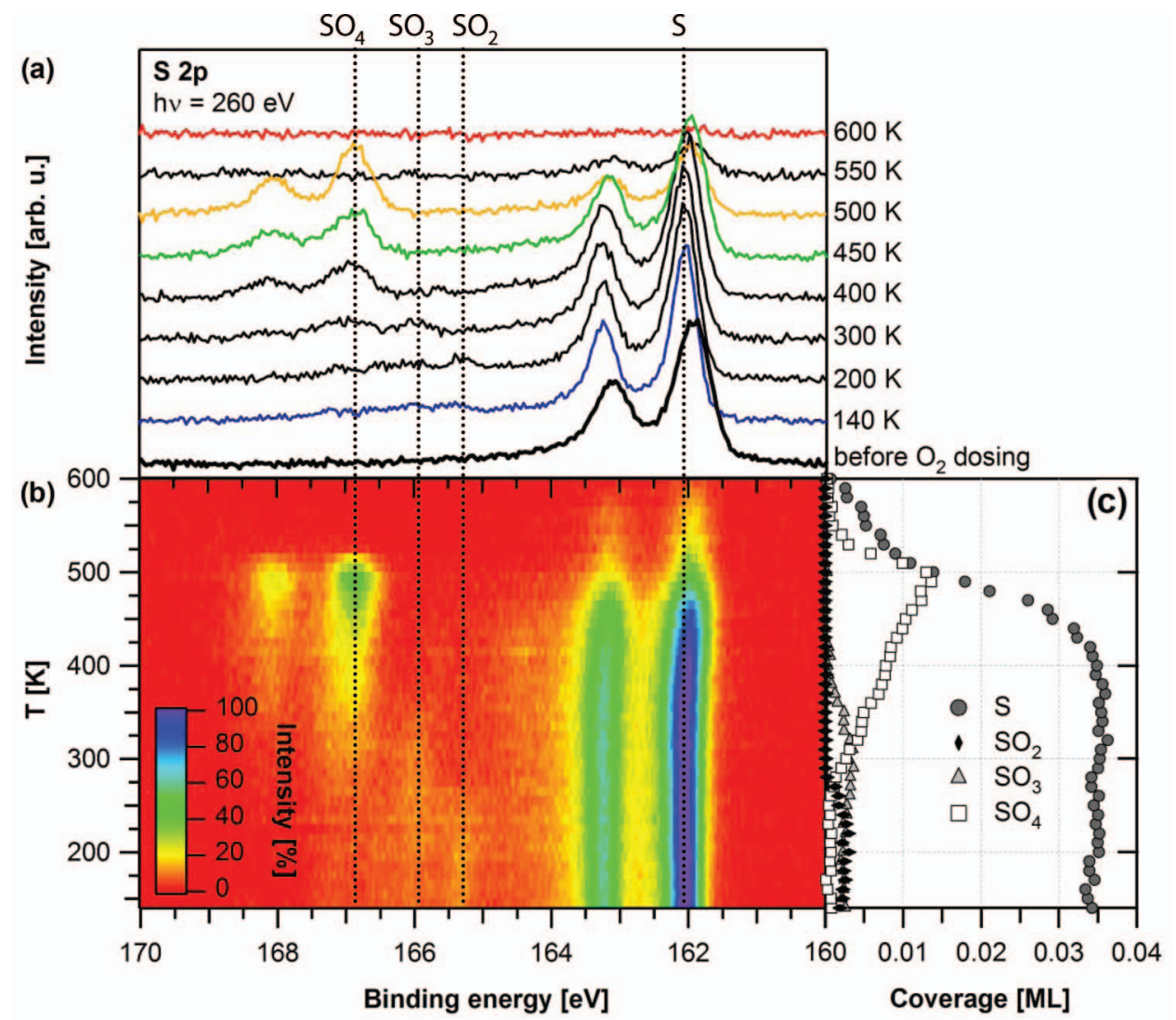

FIG. 1. TPXPS of 0.034 ML sulfur coadsorbed with $0.23 \mathrm{ML}$ of oxygen on $\mathrm{Pd}(100), \beta=0.5 \mathrm{~K} \mathrm{~s}^{-1}$ (a) selected spectra; (b) color-coded density plot, dotted lines indicate the binding energy of S $2 p_{3 / 2}$ contributions; (c) quantitative analysis.

towards higher binding energies, which is attributed to the lateral interactions with coadsorbed atomic oxygen. The shift to higher binding energies is in fair agreement with the computational estimates, which show a CLS shift of $\sim 0.3 \mathrm{eV}$ when changing from the adsorption of $\mathrm{S}$ atoms on a clean to a Pd(100) surface covered with oxygen $0.25 \mathrm{ML}$.

Additionally, a diffuse increase in intensity is observed at binding energies between 165 and $168 \mathrm{eV}$, indicating that small amounts of sulfur are already oxidized at $140 \mathrm{~K}$. The corresponding peaks at $165.3(166.5)$ and $165.9(167.1) \mathrm{eV}$ are assigned to $\mathrm{SO}_{2}$ and $\mathrm{SO}_{3}$, respectively, according to CLS estimates from an earlier study on $\mathrm{Pd}(100)^{36}$ given in Table I. These shifts are also in agreement with previous studies on $\mathrm{Pt}(111){ }^{25,45} \mathrm{In}$ an earlier study of the adsorption of $\mathrm{SO}_{2}$ on clean and oxygen precovered $\mathrm{Pd}(100)$ two different $\mathrm{SO}_{2}$ surface species were found, a majority of species standing upright $\left(\mathrm{SO}_{2}\left(\eta^{2}\right)\right)$ and a minority species lying flat $\left(\mathrm{SO}_{2}\left(\eta^{3}\right)\right)$ on the surface. ${ }^{36}$ In the present study only the more stable, upright standing $\mathrm{SO}_{2}\left(\eta^{2}\right)$ is observed. This is, however, in agree-

TABLE I. Calculated and experimentally determined relative S $2 p$ binding energies in $\mathrm{eV}$, referenced to atomic sulfur (at $161.9 \mathrm{eV}$ ). The denoted value ranges correspond to different possible adsorption conformations with respect to oxygen adatoms. ${ }^{36}$

\begin{tabular}{lcccc}
\hline \hline$\Delta \mathrm{E}[\mathrm{eV}]$ & $\mathrm{SO}_{2}\left(\eta^{1}\right)$ & $\mathrm{SO}_{2}\left(\eta^{2}\right)$ & $\mathrm{SO}_{3}$ & $\mathrm{SO}_{4}$ \\
\hline $\mathrm{HR}-\mathrm{XPS}$ & $\ldots$ & 3.4 & 4.0 & $4.9-5.5$ \\
$\mathrm{DF}^{\mathrm{a}}$ & 3.3 & 3.5 & $4.3-4.4$ & $5.3-5.4$ \\
\hline
\end{tabular}

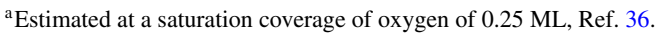

ment with the earlier results, as the $\mathrm{SO}_{2}\left(\eta^{3}\right)$ species were detected at low temperatures, $\sim 110 \mathrm{~K}$, and transformed gradually into $\mathrm{SO}_{2}\left(\eta^{2}\right)$ when annealing to higher temperatures. ${ }^{36}$

Nevertheless, it is worth to point out that a third $\mathrm{SO}_{2}$ species could play a role here, namely $\mathrm{SO}_{2}\left(\eta^{1}\right)$. According to past DF calculations, on clean $\operatorname{Pd}(100)$ these species are estimated to be $15 \mathrm{~kJ} \mathrm{~mol}^{-1}$ less stable than $\mathrm{SO}_{2}\left(\eta^{2}\right)$. However, in the presence of oxygen, especially at high oxygen coverages, it becomes the most stable $\mathrm{SO}_{2}$ adsorbate species, see Table S3 in Ref. 36. This is attributed to differences in the steric repulsion between the oxygen atoms and the different $\mathrm{SO}_{2}$ species: $\mathrm{In}$ the presence of oxygen atoms all $\mathrm{SO}_{2}$ species are destabilized, but the destabilization for $\mathrm{SO}_{2}\left(\eta^{3}\right)$ and $\mathrm{SO}_{2}\left(\eta^{2}\right)$ is $58 \mathrm{~kJ} \mathrm{~mol}^{-1}$ and $52 \mathrm{~kJ} \mathrm{~mol}^{-1}$, respectively, but only $40 \mathrm{~kJ} \mathrm{~mol}^{-1}$ for $\mathrm{SO}_{2}\left(\eta^{1}\right)$. The lower degree of destabilization of $\mathrm{SO}_{2}\left(\eta^{1}\right)$ is explained by the fact that both oxygen atoms are pointing towards the vacuum, thus reducing the steric repulsion. As far as the CLS are concerned, $\mathrm{SO}_{2}\left(\eta^{2}\right)$ and $\mathrm{SO}_{2}\left(\eta^{1}\right)$ display similar values (see Table I), indicating that the presence of both species is in agreement with the observed spectra. However, for simplicity, we hereafter will refer only to the $\mathrm{SO}_{2}\left(\eta^{2}\right)$ case.

Upon heating to temperatures above $250 \mathrm{~K}$, a (comparably broad) doublet evolves at around 166.9 (168.1) eV, initially at the cost of the $\mathrm{SO}_{2}$ and $\mathrm{SO}_{3}$ peaks. This binding energy value lies in the value range found for $\mathrm{SO}_{4}$ when studying the thermal evolution of $\mathrm{SO}_{2}$ coadsorbed with oxygen on $\mathrm{Pd}(100)$. There two different $\mathrm{SO}_{4}$ species, one in the vicinity of oxygen adatoms and one remote from oxygen 
adatoms, were observed at $166.8(168.0) \mathrm{eV}$ and at 167.4 (168.6) eV, respectively. ${ }^{36}$ From this comparison, we attribute the comparably large width of the $2 p_{3 / 2}$ and $2 p_{1 / 2}$ components to the coexistence of $\mathrm{SO}_{4}$ species bound in different proximities to oxygen on the surface. Since the binding energy value of 166.9 (168.1) eV observed in Figure 1(a) is very close to that of the $\mathrm{SO}_{4}$ species neighbouring oxygen adatoms, we conclude a higher coverage of this species than that of the $\mathrm{SO}_{4}$ species bound remotely from oxygen adatoms. This is in line with the DF results, which show a stabilization of $\mathrm{SO}_{4}$ species by neighboring $\mathrm{O}$ atoms, especially at an $\mathrm{O}$ coverage of $0.25 \mathrm{ML}$.

The thermal evolution of sulfur coadsorbed with oxygen can be followed in detail from the density plot in Figure 1(b) and from the quantitative analysis in Figure 1(c). Initially, i.e., at, $140 \mathrm{~K}, 0.034 \mathrm{ML}$ of atomic sulfur are present along with only very minor amounts of $\mathrm{SO}_{2}, \mathrm{SO}_{3}$, and $\mathrm{SO}_{4}$ (in total less than $0.01 \mathrm{ML}$ ). Around $250 \mathrm{~K} \mathrm{SO}_{2}$ starts to decrease and a slight increase in $\mathrm{SO}_{3}$ and $\mathrm{SO}_{4}$ coverage is observed. Already at $280 \mathrm{~K}$ no $\mathrm{SO}_{2}$ is left on the surface, and both $\mathrm{SO}_{3}$ and $\mathrm{SO}_{4}$ continue to grow. The $\mathrm{SO}_{3}$ coverage reaches a maximum of $\sim 0.004 \mathrm{ML}$ at $310 \mathrm{~K}$ and thereafter decreases until no $\mathrm{SO}_{3}$ is left at $400 \mathrm{~K}$. The $\mathrm{SO}_{4}$ coverage further increases to a maximum of $0.014 \mathrm{ML}$ at $490 \mathrm{~K}$, thereafter vanishing at $560 \mathrm{~K}$. This agrees with a sequential formation of species as

$$
\mathrm{SO}_{2} \rightarrow \mathrm{SO}_{3} \rightarrow \mathrm{SO}_{4},
$$

i.e., $\mathrm{SO}_{2}$ reacts with oxygen to form $\mathrm{SO}_{3}$, and subsequently $\mathrm{SO}_{3}$ reacts likewise with oxygen to form $\mathrm{SO}_{4}$.

Also it is noteworthy that the atomic sulfur coverage stays almost constant at $0.034 \mathrm{ML}$ up to $410 \mathrm{~K}$, where it starts to decrease. The decay accelerates until the inflection point at $480 \mathrm{~K}$ and is completed at $600 \mathrm{~K}$. At this temperature no sulfur-containing species are detected on the $\operatorname{Pd}(100)$ surface. Thus, it seems that the $\mathrm{SO}_{4}$ coverage is growing at the expense of $\mathrm{SO}_{2}$ and $\mathrm{SO}_{3}$ species up to a temperature of $400 \mathrm{~K}$. At higher temperatures $\mathrm{S}$ adatoms appear to react directly to $\mathrm{SO}_{4}$. This indicates that the energy barriers for the $\mathrm{SO}_{2} \rightarrow \mathrm{SO}_{3}$ and $\mathrm{SO}_{3} \rightarrow \mathrm{SO}_{4}$ conversions are small, and that the rate limiting step is the oxidation of sulfur adatoms. The remaining oxygen coverage after the experiment, $0.14 \mathrm{ML}$, indicates that most sulfur is desorbing from the surface as $\mathrm{SO}_{3}$ : If all sulfur would eventually desorb as $\mathrm{SO}_{2} 0.16 \mathrm{ML}$ of oxygen would be expected to be left on the surface after the experiment as compared to $0.13 \mathrm{ML}$ for exclusive desorption of $\mathrm{SO}_{3}$.

This reaction mechanism is fully supported by the reaction energy profiles obtained from DF calculations, as shown in Figure 2. Note that for the construction of the reaction energy profiles we have assumed that the atomic oxygen content on the surface is kept constant during the whole reaction. Because the formation of $\mathrm{SO}_{\mathrm{x}}$ species implies the incorporation of oxygen, this means we assume an external supply of oxygen. Two reaction energy profiles are displayed, corresponding to oxygen coverages of 0.125 and $0.25 \mathrm{ML}$. For each oxygen coverage the reference situation defining zero energy is given by $\mathrm{S}$ adatoms adsorbed on the $\mathrm{Pd}(100)$ surrounded by a number of oxygen atoms corresponding to the given oxygen coverage. The two scenarios displayed in Figure 2 should be regarded as the two extremes. In the beginning of the experi-

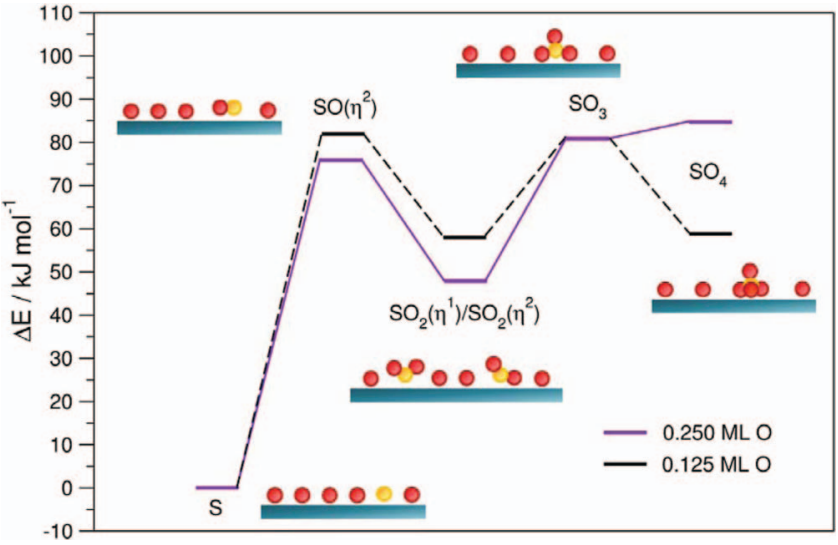

FIG. 2. Reaction energy profiles for the sequential oxidation of sulfur atoms on Pd(100) for constant coverages of atomic oxygen of $0.250 \mathrm{ML}$ (violet solid lines) and of $0.125 \mathrm{ML}$ (black dashed lines). In the sketches, the turquoise bar represents the $\operatorname{Pd}(100)$ surface while red and yellow spheres represent oxygen and sulfur atoms, respectively.

ment, the sulfur atoms are surrounded by $0.23 \mathrm{ML}$ of oxygen, while at the final stage at $600 \mathrm{~K}$, the $\mathrm{S}$ and $\mathrm{SO}_{\mathrm{X}}$ species, are surrounded by a lower oxygen coverage of $0.13 \mathrm{ML}$. Thus, at the initial stages the path will resemble more that calculated at $0.25 \mathrm{ML}$ oxygen, whereas at the final stages the one at $0.125 \mathrm{ML}$ coverage of atomic oxygen is more relevant.

According to the reaction paths the rate limiting step is the formation of in-plane $\mathrm{SO}\left(\eta^{2}\right)$. The difference in energy is $76-82 \mathrm{~kJ} \mathrm{~mol}^{-1}$. Such an endothermic step would suggest a late transition state near the $\mathrm{SO}\left(\eta^{2}\right)$ energy level. After that two different mechanisms would be possible to form $\mathrm{SO}_{2}\left(\eta^{2}\right) / \mathrm{SO}_{2}\left(\eta^{1}\right)$. One would imply that $\mathrm{SO}\left(\eta^{2}\right)$ transforms into the more stable $\mathrm{SO}\left(\eta^{1}\right)$ species by breaking the $\mathrm{O}-\mathrm{Pd}$ bond, and later on forming $\mathrm{SO}_{2}$ by further incorporating an oxygen atom. The other one implies that $\mathrm{SO}\left(\eta^{2}\right)$ is directly transformed into $\mathrm{SO}_{2}\left(\eta^{2}\right)$ or $\mathrm{SO}_{2}\left(\eta^{1}\right)$, probably through in-plane addition of oxygen forming the flat lying $\mathrm{SO}_{2}\left(\eta^{3}\right)$ species, and later on forming $\mathrm{SO}_{2}\left(\eta^{2}\right)$ or $\mathrm{SO}_{2}\left(\eta^{1}\right)$ by breaking one or two $\mathrm{O}-\mathrm{Pd}$ bonds, respectively. Further oxidation into $\mathrm{SO}_{3}$ is also endothermic, but only by $23-33 \mathrm{~kJ} \mathrm{~mol}^{-1}$. Finally, the formation of $\mathrm{SO}_{4}$ is isoenergetic at oxygen saturation, but slightly exothermic by $\sim 22 \mathrm{~kJ} \mathrm{~mol}^{-1}$ at $0.125 \mathrm{ML}$ of atomic oxygen. This is also in excellent agreement with the TPXPS results shown in Figure 1(c). In the experiment we observe, after overcoming the highest energy barrier, that the large excess of oxygen is shifting the equilibrium towards the higher oxidized species such as $\mathrm{SO}_{2}, \mathrm{SO}_{3}$, and $\mathrm{SO}_{4}$. The sequential oxidation of $\mathrm{SO}_{2}$ is thermodynamically possible and the final product on the surface is $\mathrm{SO}_{4}$. Moreover from the energy diagram in Fig. 2, the observed desorption of $\mathrm{SO}_{3} / \mathrm{SO}_{2}$ at high temperature is explained, as the $\mathrm{SO}_{4}$ species can easily react backwards to form $\mathrm{SO}_{3}$ or $\mathrm{SO}_{2}$. The complete oxidation of $\mathrm{S}$ to $\mathrm{SO}_{4}$, without desorption of $\mathrm{SO}_{2}$ and $\mathrm{SO}_{3}$, is possible due to the fact that their desorption (adsorption) energies of $90-150 \mathrm{~kJ} \mathrm{~mol}^{-1}$ are obviously higher than the energy required for $\mathrm{SO}_{4}$ formation. At higher temperatures, on the other hand, desorption is possible after backreaction from $\mathrm{SO}_{4}$. 


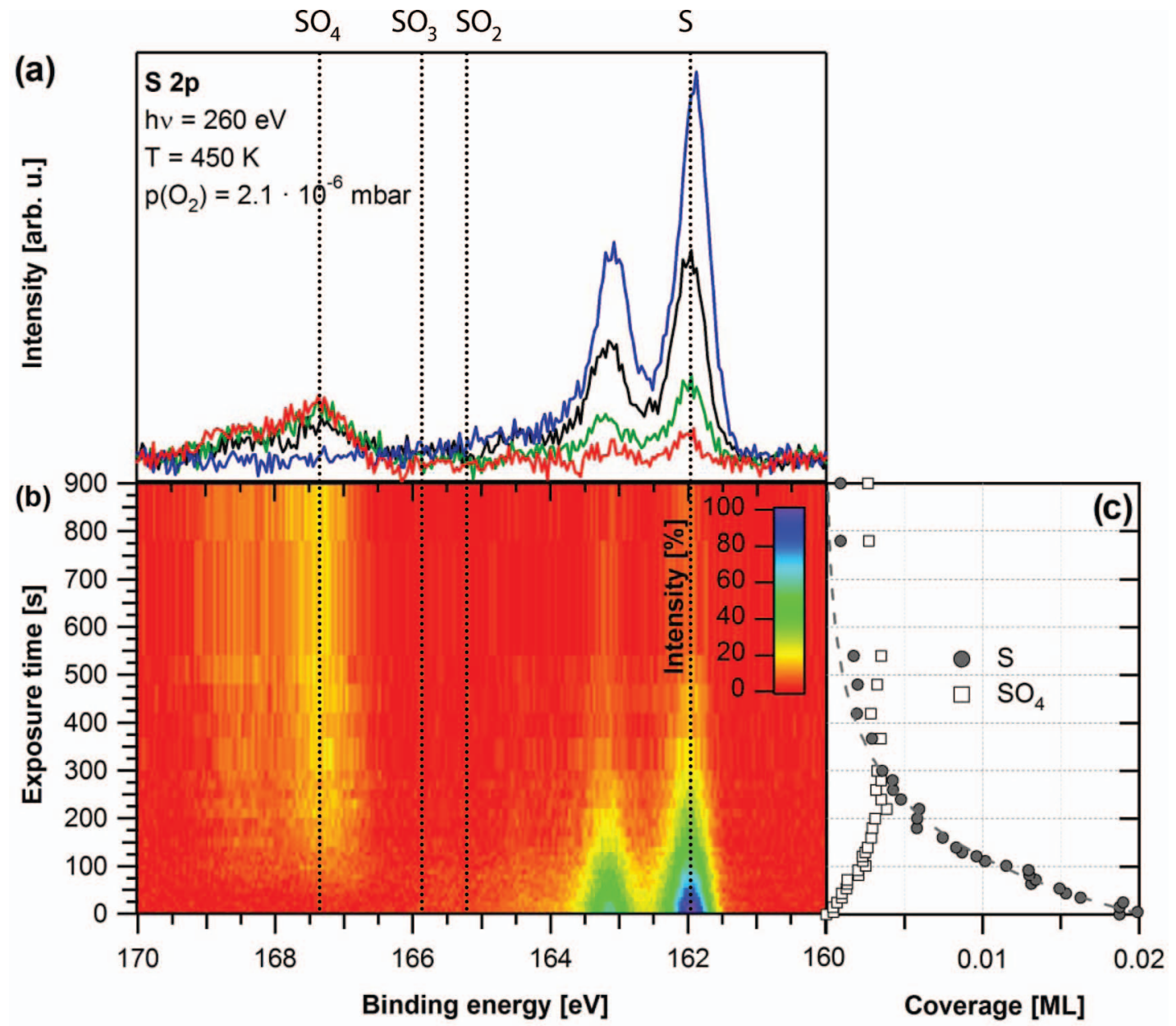

FIG. 3. Isothermal oxidation of sulfur on $\mathrm{Pd}(100)$ at $450 \mathrm{~K}$; (a) selected spectra: spectrum recorded before oxygen adsorption (blue), spectra recorded after $100 \mathrm{~s}$ (black), $300 \mathrm{~s}$ (green) and $900 \mathrm{~s}$ (red) of oxygen uptake, respectively; (b) corresponding density plot, dotted lines indicate the BE of S $2 p_{3 / 2}$ contributions; (c) quantitative analysis.

From the preparation it is known that atomic sulfur is not desorbing from the clean surface at temperatures below $600 \mathrm{~K}$. Hence, it is concluded that all preadsorbed atomic sulfur is oxidized and desorbed from the surface thereafter as $\mathrm{SO}_{\mathrm{x}}$.

Overall, the reaction can be summarized as

$$
\mathrm{S} \rightarrow(\mathrm{SO}) \rightarrow \mathrm{SO}_{2} \rightarrow \mathrm{SO}_{3} \rightarrow \mathrm{SO}_{4}
$$

where $\mathrm{SO}$ is an unobserved intermediate necessary for the oxidation of $\mathrm{S}$ into $\mathrm{SO}_{2}$. Note that this shows that the further oxidation of $\mathrm{SO}$ is a rapid reaction step.

Previous studies on the thermal evolution of $\mathrm{SO}_{2}$ adsorbed on oxygen precovered $\mathrm{Pd}(100)$ showed that the decomposition of $\mathrm{SO}_{4}$ starts around $450 \mathrm{~K}$. The coverage maximum of $\mathrm{SO}_{4}$ at $490 \mathrm{~K}$ therefore results from two competing reactions: $\mathrm{SO}_{4}$ formation and $\mathrm{SO}_{4}$ decomposition, accompanied by subsequent desorption of the sulfur containing decomposition products, typically $\mathrm{SO}_{2}$ or $\mathrm{SO}_{3}$, the only $\mathrm{SO}_{x}$ species stable in the gas phase. Therefore the amount of $\mathrm{SO}_{4}$ on the surface can never be as high as the original amount of atomic sulfur. As already mentioned, this agrees with the reaction energy profile in Figure 2, as the reaction from $\mathrm{SO}_{3}$ to $\mathrm{SO}_{4}$ as well as the backwards reaction is energetically not demanding. Moreover, both $\mathrm{SO}_{2}$ and $\mathrm{SO}_{3}$ show similar adsorption strengths.

From the above analysis we deduce that the oxidation of sulfur on the $\operatorname{Pd}(100)$ surface mainly occurs between 400 and $500 \mathrm{~K}$. In order to determine the kinetics of the reaction we performed in situ XPS under isothermal conditions within this temperature range. A representative set of spectra is shown in Figure 3; here the data were collected at $450 \mathrm{~K}$ with an initial sulfur coverage of $0.020 \mathrm{ML}$ and with an effective oxygen pressure of $2.1 \times 10^{-6}$ mbar on the sample. The relatively small sulfur coverage was chosen to allow for a large excess of oxygen on the surface during the reaction, thus leading to pseudo first order conditions as will be further discussed below. The spectrum recorded before the start of oxygen dosage (blue curve in Figure 2(a)) displays the sulfur doublet at $161.9 \mathrm{eV}$.

After starting the oxygen dosage the sulfur coverage decreases rapidly and a broad doublet at $\sim 167.3 \mathrm{eV}$ emerges. This doublet is again assigned to $\mathrm{SO}_{4}$. The $\mathrm{SO}_{4}$ coverage increases with time and saturates around $300 \mathrm{~s}$ at roughly $0.003 \mathrm{ML}$, as evident from the quantitative analysis in Figure 2(c). Here $\mathrm{SO}_{2}$ and $\mathrm{SO}_{3}$ are not shown because their amounts are negligible in comparison to sulfur and $\mathrm{SO}_{4}$. After $900 \mathrm{~s}$ almost all atomic sulfur on the surface has been 
oxidized to $\mathrm{SO}_{4}$; the amount of $\mathrm{S}$ and $\mathrm{SO}_{4}$ left on the surface corresponds to less than $20 \%$ of the initial amount of $\mathrm{S}$, as evident from Figure 3(c). This clearly indicates that the vast majority of the oxidized sulfur has desorbed from the surface. The decay of the sulfur signal can be fitted with an exponential function (dashed grey line in Figure 3(c)). The good agreement shows that the rate limiting step of the reaction follows almost perfectly a pseudo first order behavior. Since no $\mathrm{SO}$, but only $\mathrm{SO}_{2}, \mathrm{SO}_{3}$, and $\mathrm{SO}_{4}$ are detected as reaction intermediates, the rate limiting step must be the reaction of atomic sulfur and oxygen to SO, as described in Figure 2, and similar to the situation found on $\mathrm{Pt}(111)$ and $\mathrm{Pt}(355) .{ }^{28}$

In addition, isothermal experiments were also performed at $400,425,475$, and $500 \mathrm{~K}$ with an oxygen pressure of 2.1 $\times 10^{-6}$ mbar. Note that the initial precoverages of sulfur varied between 0.014 and $0.025 \mathrm{ML}$, which does, however, not affect the data analysis and the derived conclusions. The corresponding quantitative analysis of the $S$ coverage is shown in Figure 4(a). With increasing temperature the decrease of the normalized $\mathrm{S}$ peak area occurs more rapidly, i.e., for 500 and $475 \mathrm{~K}$ the reaction is completed after 60 and $130 \mathrm{~s}$, respectively; in both cases less than $6 \%(<0.002 \mathrm{ML})$ of the initial sulfur coverage is left on the surface. For 450,425 , and $400 \mathrm{~K}$ the amount of sulfur remaining after $900 \mathrm{~s}$ corresponds to $7 \%$, $30 \%$, and $61 \%$ of the initial coverage. The logarithmic plots of the normalized S peak area versus time in Figure 4(b) show straight lines for all temperatures, again indicating that the reaction is pseudo first order with respect to sulfur. The reaction rate constants $k_{o b s}$ were obtained by linear fitting of the data in Figure 4(b). Note that in the experiment at $450 \mathrm{~K}$ the data for long exposure times, i.e., very low sulfur coverages, deviates from a line. Therefore here only the first part of the graph was used for the fitting.

It is interesting to note that test experiments with a lower oxygen pressure of $1.4 \times 10^{-6}$ mbar (data not shown) show that the reaction deviates from the first order behaviour seen in Figure 4(a); indicating that at this point oxygen is obviously not available in excess, at least in the close vicinity of the remaining sulfur atoms, and thus the conditions for pseudo first order behaviour are not fulfilled. A second possible reason is that the remaining sulfur atoms are adsorbed in special defect sites, which makes them more resistive towards oxidation.

By plotting the rate constants derived from Figure 4(b) in an Arrhenius plot (see Figure 4(c)), the activation energy for the sulfur oxidation is determined to be $85 \pm 6 \mathrm{~kJ} \mathrm{~mol}^{-1}$. This value is in good agreement with the endothermicity of the $\mathrm{SO}\left(\eta^{2}\right)$ formation, as shown by DF calculations defining the reaction energy path depicted in Figure 2. Such an endothermic process typically is accompanied by a late transition state very close in energy to the product state. Thus, the activation energy is determined by the thermodynamic situation, i.e., the energetic difference in educts and products, being close to the experimental value observed here. In the similar system $\mathrm{Pt}(111)$ the energy barrier is smaller: $74 \pm 4 \mathrm{~kJ}$ $\mathrm{mol}^{-1} \cdot{ }^{28}$ Interestingly, on $\mathrm{Pt}(111)$ significant amounts of $\mathrm{SO}_{3}$ were observed during the oxidation, while on $\mathrm{Pd}(100)$ the $\mathrm{SO}_{4}$ species is the dominating product and reaction intermediates such as $\mathrm{SO}_{2}$ and $\mathrm{SO}_{3}$ were found only in very minor amounts; this can be partly explained by the fact that $\mathrm{SO}_{4}$ is more stable
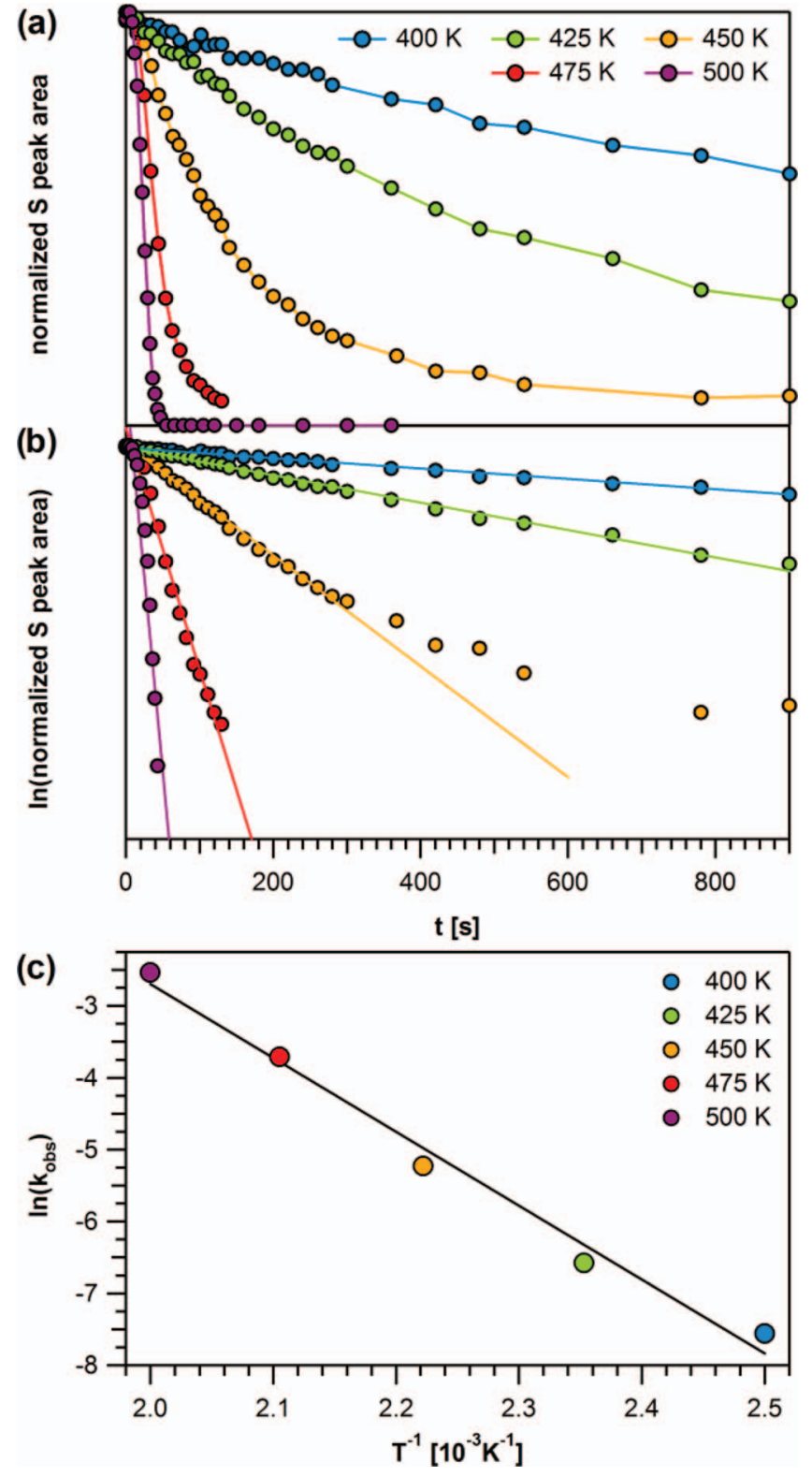

FIG. 4. Quantitative analysis of the atomic sulfur signal during isothermal oxidation at different temperatures; $500 \mathrm{~K}: \Theta_{\mathrm{S}}(0)=0.01 \mathrm{ML}, 475 \mathrm{~K}: \Theta_{\mathrm{S}}(0)$ $=0.03 \mathrm{ML}, 450 \mathrm{~K}: \Theta_{\mathrm{S}}(0)=0.02 \mathrm{ML}, 425 \mathrm{~K}: \Theta_{\mathrm{S}}(0)=0.02 \mathrm{ML}, 400 \mathrm{~K}:$ $\Theta_{\mathrm{S}}(0)=0.02 \mathrm{ML}$; (a) linear plot; lines are a guide to the eye; (b) logarithmic plot; lines correspond to linear fits; (c) Arrhenius plot for sulfur oxidation at different temperatures.

on $\operatorname{Pd}(100)$ than on $\operatorname{Pt}(111)$ by $\sim 53 \mathrm{~kJ} \mathrm{~mol}^{-1}$, when comparing previous calculations of the adsorption energy of $\mathrm{SO}_{4}$ on pristine $\mathrm{Pd}(100)$ and $\mathrm{Pt}(111)$ surfaces. ${ }^{25,36}$ Nevertheless, one can not rule out different formation rates of $\mathrm{SO}_{3}$ and $\mathrm{SO}_{4}$ for the two surfaces.

Another noteworthy difference to $\mathrm{Pt}(111)$ is the observation that the amount of remaining sulfur after annealing an $\mathrm{SO}_{2}$ layer to elevated temperatures is much higher on $\operatorname{Pd}(100)$. This is also in line with the fact that, according to present and past calculations at the same DF level, ${ }^{25,36}$ atomic sulfur is more stable on $\operatorname{Pd}(100)$ than on $\operatorname{Pt}(111)$, by $\sim 45 \mathrm{~kJ}$ $\mathrm{mol}^{-1}$. Since in addition the activation barrier for oxidation is 
higher for $\operatorname{Pd}(100)$, we expect an easier reactivation by oxidation of sulfur-poisoned Pt than Pd.

\section{CONCLUSIONS}

It is shown that small amounts of sulfur can be removed from the Pd(100) surface effectively by oxidation with molecular oxygen at temperatures between 400 and $500 \mathrm{~K}$, based on a series of temperature programmed $\mathrm{x}$-ray photoemission spectroscopy experiments and $a b$ initio density functional calculations. In an oxygen-rich environment, atomic sulfur is oxidized to $\mathrm{SO}_{4}$ and desorbs subsequently as $\mathrm{SO}_{\mathrm{x}}(\mathrm{x}=2-3)$. Only small surface coverages of the reaction intermediates $\mathrm{SO}_{2}$ and $\mathrm{SO}_{3}$ were detected while $\mathrm{SO}$ was not observed at all, suggesting that the rate limiting step is the reaction of sulfur and oxygen adatoms to form $\mathrm{SO}$ with an activation energy of $85 \pm 6 \mathrm{~kJ} \mathrm{~mol}^{-1}$. Density-functional calculations depict a reaction energy profile that supports this process as the rate limiting step. The endothermicity of the SO formation seems to be the most demanding energetic step, matching the experimentally determined activation energy.

\section{ACKNOWLEDGMENTS}

The authors gratefully acknowledge the funding of Bundesministerium fuer Bildung, Forschung und Technologie (BMBF) (Grant No. 05 ES3XBA15) and of the German Research Council (DFG), which, within the framework of its "Excellence Initiative," supports the Cluster of Excellence "Engineering of Advanced Materials" (www.eam.unierlangen.de) at the University of Erlangen-Nuremberg. F.V. thanks the Alexander von Humboldt Foundation for his postdoctoral grant. We thank Berliner ElektronenspeicherringGesellschaft für Synchrotronstrahlung (BESSY) staff for their support during beamtime.

${ }^{1}$ M. Bowker, Chem. Soc. Rev. 37, 2204 (2008).

${ }^{2}$ J. A. Rodriguez, P. Liu, Y. Takahasi, K. Nakamura, F. Viñes, and F. Illas, Top. Catal. 53, 393 (2010).

${ }^{3}$ J. Han, D. Y. Zemlyanov, and F. H. Ribeiro, Catal. Today 117, 506 (2006).

${ }^{4}$ S. Royer and D. Duprez, ChemCatChem 3, 24 (2011).

${ }^{5}$ C. Marcilly, J. Catal. 216, 47 (2001).

${ }^{6}$ H.-U. Blaser, A. Indolese, A. Schnyder, H. Steiner, and M. Studer, J. Mol. Catal. A: Chem. 173, 3 (2001).

${ }^{7}$ A. V. Slack and G. A. Holliden, Sulfur Dioxide Removal from Waste Gases (Noyes Data Corp., Park Ridge, NJ, 1975).

${ }^{8}$ N. Luckas, F. Viñes, M. Happel, A. Desikusumastuti, J. Libuda, and A. Görling, J. Phys. Chem. C 114, 13813 (2010).
${ }^{9}$ J. A. Rodriguez, T. Jirsak, S. Chaturvedi, and J. Hrbek, J. Am. Chem. Soc. 120, 11149 (1998).

${ }^{10}$ P. Albers, J. Pietsch, and S. F. Parker, J. Mol. Catal. A: Chem. 173, 275 (2001).

${ }^{11}$ J. A. Rodriguez and J. Hrbek, Acc. Chem. Res. 32, 719 (1999).

${ }^{12}$ T. C. Ho, Catal. Today 98, 3 (2004).

${ }^{13}$ R. Burch, D. J. Crittle, B. W. L. Southward, and J. A. Sullivan, Catal. Lett. 72, 153 (2001)

${ }^{14}$ S. Colussi, F. Arosio, T. Montanari, G. Busca, G. Groppi, and A. Trovarelli, Catal. Today 155, 59 (2010).

${ }^{15}$ D. L. Mowery, M. S. Graboski, T. R. Ohno, and R. L. McCormick, Appl. Catal., B 21, 157 (1999).

${ }^{16}$ S. Ordóñez, P. Hurtado, and F. V. Díez, Catal. Lett. 100, 27 (2005).

${ }^{17}$ A. Shamsi, Catal. Today 139, 268 (2009).

${ }^{18}$ T.-C. Yu and H. Shaw, Appl. Catal., B 18, 105 (1998)

${ }^{19}$ D. W. Goodman, Appl. Surf. Sci. 19, 1 (1984).

${ }^{20}$ D. R. Alfonso, Surf. Sci. 600, 4508 (2006).

${ }^{21}$ I. Makkonen, P. Salo, M. Alatalo, and T. S. Rahman, Phys. Rev. B 67, 165415 (2003).

${ }^{22}$ S. Wilke and M. Scheffler, Phys. Rev. Lett. 76, 3380 (1996).

${ }^{23}$ W. Berndt, R. Hora, and M. Scheffler, Surf. Sci. 117, 188 (1982).

${ }^{24}$ D. Kolthoff, D. Jürgens, C. Schwennicke, and H. Pfnür, Surf. Sci. 365, 374 (1996).

${ }^{25}$ M. Happel, N. Luckas, F. Viñes, M. Sobota, M. Laurin, A. Görling, and J. Libuda, J. Phys. Chem. C 115, 479 (2011).

${ }^{26}$ N. D. Lang, S. Holloway, and J. K. Nørskov, Surf. Sci. 150, 24 (1985).

${ }^{27}$ M. Lahti, A. Puisto, M. Alatalo, and T. S. Rahman, Surf. Sci. 602, 3660 (2008).

${ }^{28}$ R. Streber, C. Papp, M. P. A. Lorenz, A. Bayer, R. Denecke, and H.-P. Steinrück, Angew. Chem., Int. Ed. 48, 9743 (2009).

${ }^{29}$ J. G. Kölzer and H.-W. Wassmuth, Ann. Phys. 498, 472 (1986).

${ }^{30}$ R. Denecke, M. Kinne, C. M. Whelan, and H.-P. Steinrück, Surf. Rev. Lett. 9, 797 (2002).

${ }^{31}$ A. Baraldi, G. Comelli, S. Lizzit, D. Cocco, G. Paolucci, and R. Rosei, Surf. Sci. Lett. 367, L67 (2006).

${ }^{32}$ D. Shirley, Phys. Rev. B 5, 4709 (1972).

${ }^{33}$ S. Doniach and M. Šunjić, J. Phys. C 3, 285 (1970).

${ }^{34}$ G. Kresse and J. Furthmüller, Phys. Rev. B 54, 11169 (1996).

${ }^{35}$ P. E. Blöchl, Phys. Rev. B 50, 17953 (1994).

${ }^{36}$ N. Luckas, K. Gotterbarm, R. Streber, M. P. A. Lorenz, O. Höfert, F. Viñes, C. Papp, A. Görling, and H.-P. Steinrück, Phys. Chem. Chem. Phys. 13, 16227 (2011).

${ }^{37}$ X. Lin, K. C. Hass, W. F. Schneider, and B. L. Trout, J. Phys. Chem. B 106, 12575 (2002).

${ }^{38}$ X. Lin, W. F. Schneider, and B. L. Trout, J. Phys. Chem. B 108, 250 (2003).

${ }^{39}$ X. Lin, W. F. Schneider, and B. L. Trout, J. Phys. Chem. B 108, 13329 (2004).

${ }^{40}$ J. P. Perdew and Y. Wang, Phys. Rev. B 45, 13244 (1992).

${ }^{41}$ L. Köhler and G. Kresse, Phys. Rev. B 70, 165405 (2004).

${ }^{42}$ R. Streber, B. Tränkenschuh, J. Schöck, C. Papp, H.-P. Steinrück, J. S. McEwen, P. Gaspard, and R. Denecke, J. Chem. Phys. 131, 064702 (2009).

${ }^{43}$ H. Tang and B. L. Trout, J. Phys. Chem. B 109, 6948 (2005).

${ }^{44}$ J. F. Janak, Phys. Rev. B 18, 7165 (1978).

${ }^{45}$ R. Streber, C. Papp, M. P. A. Lorenz, O. Höfert, E. Darlatt, A. Bayer, R. Denecke, and H.-P. Steinrück, Chem. Phys. Lett. 494, 188 (2010). 